\title{
O impacto da formação inicial de professores nas apresentações digitais em educação
}

\section{The impact of initial teacher education in digital presentations in education}

\author{
João Batista de Moura (MOURA, João B. de)*, Lia Raquel Moreira Oliveira (OLIVEIRA, Lia R.)** \\ * Instituto Federal do RN - Natal, Brasil., ** Universidade do Minho - Braga, Portugal.
}

\begin{abstract}
Resumo
Esta é uma pesquisa de natureza qualitativa que tem como meta investigar o impacto da formação midiática em dois grupos de licenciandos, especificamente a produção e a reflexividade sobre apresentações digitais educativas. A investigação trata, portanto, dos pressupostos epistemológicos, filosóficos e metodológicos referentes ao debate em torno das apresentações digitais projetadas, com ou sem interferências áudio-scripto-visuais, assim como o uso destes recursos midiáticos em ambiente educacional, a sistemática de produção, a reflexividade dos produtores em relação a superação das dificuldades e desafios, bem como os saberes, as competências e habilidades adquiridas no processo de formação.
\end{abstract}

Palavras chave: apresentações digitais, interferências, formação inicial de professores, reflexividade.

\begin{abstract}
This is a qualitative research that aims to investigate the impact of media training in two groups of licentiate students, specifically in the production and reflexivity about educational digital presentations. The research deals with the epistemological, philosophical and methodological assumptions concerning the debate on projected digital presentations, with or without audio-scripto-visual interferences, as well as the use of these media resources in educational setting, the systematic of production, the reflexivity of the producers towards overcoming the difficulties and challenges, as well as the skills and abilities acquired in the process.
\end{abstract}

Key words: digital presentations, interferences, initial teacher education, reflexivity.

\section{Introdução}

A pesquisa objeto deste trabalho aborda uma problemática envolvendo apresentações digitais em ambiente educativo. Foi no contexto do ensino na disciplina de Mídias Educacionais, mais especificamente em turmas de Licenciaturas do Instituto Federal de Educação, Ciência e Tecnologia do RN (IFRN), Campus Natal Central, onde surgiram afirmações de ex-alunos que, após retornarem de eventos de caráter acadêmico-científico pelo Brasil, relataram para o professor-pesquisador, a presença constante de interferências áudio-scripto-visuais nas apresentações digitais, elaboradas e apresentadas, tanto por alunos, quanto por professores.

Diante da frequência de tais afirmações, semestre após semestre, ficamos intrigados e fomos induzidos a fazer uma auto-reflexão sobre o nosso trabalho. O fato de alguns alunos descreverem em detalhes um amadorismo frequente no design de apresentações digitais elaboradas por professores com mestrado e doutorado, isto é, profissionais supostamente bem preparados para apresentarem resultados de investigações científicas importantes, nos estimulou a investigar essa problemática de forma científica e sistematizada, para compreendermos os impactos, isto é, a aquisição, ou não, de competências e reflexividade, na formação midiática inicial dos licenciandos, no contexto da produção de apresentações digitais multimídia projetadas verticalmente para fins educativos.

Diante do exposto, faz-se necessário abordarmos alguns elementos epistemológicos que compõem este processo, dentre os quais destacamos as competências e reflexividade dos sujeitos, assim como alguns aspectos inerentes às produções, com e sem interferências.

\section{Competências}

Na última década, o IFRN vem adquirindo projetores digitais multimídia e lousas interativas, como forma de atender as demandas do corpo docente e discente, para integrar novos recursos tecnológicos que auxiliam no processo de ensino e aprendizagem.

O uso eficiente dos produtos midiático-educativos de projeção demanda competências especificas, além de reflexividade por parte dos usuários, para que eles possam preparar as suas próprias apresentações digitais com eficiência e profissionalismo, isto é, sem elementos áudio-scripto-visuais que interfiram na transmissão e recepção de informações inerentes ao processo de ensino, mediação e aprendizagem. No que concerne a formação das competências dos licenciandos, o documento intitulado Projeto Pedagógico do Curso Superior de Licenciatura em Espanhol do IFRN, na modalidade presencial, “...destaca o preparo para o uso de tecnologias da informação e da comunicação e de metodologias, estratégias e materiais de apoio inovadores.” IFRN (2012, p. 20). Este preceito está também de acordo com os padrões internacionais estabelecidos no documento UNESCO ICT Competency 
Framework for Teachers (UNESCO (2011), mais precisamente, no item que trata das competências do módulo pedagógico, que diz: "Os professors devem saber onde, com quem, quando (assim como quando não) e como utilizar as TICs em atividades de sala de aula e apresentações. (p. 20). Dentre as capacidades exigidas dos professors, descritas no Appendix 1 do mesmo documento, destaca-se o item "TL.3.c. usar programa de apresentação e recursos digitais como apoio ao ensino” (idem p. 24). Cabe aqui ressaltar que a expressão "presentation software" ou programa de apresentação, aparece 21 vezes neste documento da UNESCO sobre competências, o que reflete de forma inquestionável a relevancia a atualidade do tema desta investigação, principalmente no contexto da profissionalização docente a nível internacional.

\section{Reflexividade}

Um dos objetivos que consta no documento do Programa da disciplina de Mídias Educacionais do IFRN, isto é, o contexto local da pesquisa, configura-se em "utilizar recursos tecnológicos para facilitar o pensamento em níveis complexos e críticos, incluindo a resolução de problemas, construção do conhecimento e criatividade”, IFRN (2012, p. 55). Essa concepção encontra respaldo na promoção do desenvolvimento de competências relacionadas à reflexão, o pensamento crítico de alunos e professores sobre a aprendizagem com o uso das TICs, expressa no documento UNESCO ICT Competency Framework for Teachers, UNESCO (2011).

Nessa perspectiva, este trabalho encontra suporte teórico no ensino prático reflexivo, preconizado por Donald Schön nas suas obras seminais de (1983 e 2000), que abordam a "reflexão na ação" envolvendo eventos práticos que ocorrem no momento em que a ação está se desenrolando, e a "reflexão sobre a ação", que consiste em refletir sobre o que acontecerá, ou aconteceu, durante a ação.

Tendo em vista as inúmeras possibilidades que o ensino prático reflexivo oferece, decidimos envolver professores em formação inicial na investigação, para que eles pudessem refletir sobre suas próprias práticas, advindas das suas ações e experiências com o uso de programas de apresentação digital projetada.

Esta investigação, portanto, engloba a teoria, a pesquisa e a prática, na dimensão da reflexividade em contexto educacional.

\footnotetext{
Produções multimidiáticas projetadas verticalmente (com e sem interferências)

Diante da problemática, já citada, referente a presença de interferências áudio-scripto-visuais, nas apresentações digitais produzidas por alunos e professores, apontamos a seguir algumas considerações provenientes da literatura consultada.

Ao referir-se à instrução via computador, Saettler (2004) indica que avaliações feitas em meta-análises descobriram que três quartos dos estudos apontam sérias evidências de falhas (ruído/noise) no design e que existe uma tendência de exagero nos efeitos (visuais e sonoros). Zheng (2009, p. 35) corrobora esta informação,
}

apontando para estudos recentes, ao declarar que "existe uma visão unânime entre pesquisadores de que [os conteúdos em] multimídia também podem impedir o aprendizado e aumentar a carga cognitiva, se não forem desenhados adequadamente."

Programas de apresentação como o MS PowerPoint utilizam wizards e templates pré-empacotados que, segundo Peery (2011, p. 34), “não foram concebidos (originalmente) para serem usados por representantes de vendas, professores e estudantes", e sim por engenheiros. Neste caso, "forçam" leigos em design visual a os utilizar, pois são embutidos e executados automaticamente.

Tufte (2006 p. 158) faz sérias críticas ao uso de templates e à "sequencialidade" no formato dos slides utilizados em apresentações. Alley (2003 p. 139) constata que se deve "avaliar os defaults (telas padronizadas) de tais programas para determinar se esses defaults servem ao seu público, propósito e ocasião. ” Ele alerta que "nos casos em que os defaults dos programas não servem para as apresentações, então o usuário (professor) deve ser pró-ativo e mudá-los. " Nessa dialética, Abela (2008 p. 91) faz um questionamento paradigmático, "Por que culpar o software e não os seus usuários?” Gabriel (2013 p.12) complementa esta afirmação declarando que "as novas tecnologias tanto podem auxiliar como atrapalhar nos processos educacionais”.

O senso comum, induz a inserção não só de templates mas, principalmente, de elementos de design que interferem ou causam ruído/noise no canal de comunicação, Shannon e Weaver (1949), gerando uma (sobre)Carga Cognitiva que limita a memória de trabalho e dificulta a aprendizagem, Sweller (2005).

Portanto, existe uma demanda dos professores em formação para que obtenham conhecimentos específicos para aplicar princípios cognitivos, segundo Lefrançois (2009), relacionados com as percepções de padrão de Pregnância (Prägnanz/boa forma). Lefrançois (2009) indica quatro princípios elaborados pioneiramente pelo gestaltista Wertheimer: Princípio do Fechamento, da Continuidade, da Similaridade e da Proximidade. Williams (2008, p. 13), por sua vez, advoga o domínio de quatro princípios básicos de design: Proximidade, Alinhamento, Repetição e Contraste. Kosslyn (2007, p. 195) é enfático ao afirmar que "muitos designs de templates disponíveis no programa PowerPoint violam princípios de Saliência, Discriminalidade, Organização Perceptual e Mudanças Informativas.” Mayer (2003) vai mais além ao conceber a Teoria Cognitiva da Aprendizagem Multimídia, que pressupõe princípios de Multimídia; Proximidade Espacial; Proximidade Temporal; Coerência; Modalidade; Redundância e o Principio das Diferenças Individuais.

Não dominar princípios elementares de design pode resultar em apresentações amadoras com fenômenos que interferem (ruído/noise) na legibilidade e na compreensão dos conteúdos apresentados. Abela (2008, p. 5) corrobora este pensamento ao afirmar que "os maus hábitos de design evoluíram a ponto de enfraquecer de forma assustadora a eficácia das apresentações. ” 
Deste modo, um elemento essencial constitutivo desta investigação é a sistematização de conhecimentos sobre a dialética que envolve a produção de conhecimentos em forma de conteúdos Áudio-Scripto-Visuais, Cloutier (1975 [1965]), com criticidade e qualidade científica, para serem apresentados aos alunos com excelência profissional, comunicando de forma mais eficiente os conteúdos em aulas, seminários, e outras situações pedagógicas e didáticas.

Diante da problemática e dos pressupostos epistemológicos postos aqui, o tema da investigação encontra relevância, pois tem alto potencial para alterar o status-quo das práticas didático-pedagógicas do IFRN, com desdobramentos para outros investigadores interessados em conhecer mais profundamente o trabalho de licenciandos produtores de conteúdos multimídia para apresentações.

\section{Objetivos}

A pesquisa se propõe a investigar como um programa de intervenção pedagógica (formação experimental) pode impactar na formação midiática de um grupo de licenciandos, no que concerne a elaboração e grau de reflexividade concernentes ao design de slides (diapositivos) e conteúdos das suas apresentações digitais. Mais especificamente, pretende-se: estudar os pressupostos epistemológicos, filosóficos e metodológicos que envolvem a dialética da produção de slides para apresentações multimídia; identificar as percepções e competências reflexivas de um grupo de professores em formação do IFRN, em relação ao processo de produção e análise de apresentações multimídia para suas aulas; analisar os principais erros de design em slides multimídia, cometidos pelos licenciandos pesquisados, baseando-se nos princípios teóricos, didático-metodológicos subjacentes; identificar os desafios institucionais no que concerne à implementação de novos modelos tecnológico-educacionais; contribuir para uma melhor prática pedagógica na Instituição, nomeadamente, no que diz respeito à concepção de um programa de intervenção pedagógica, tendo em vista à excelência profissional necessária para o design de slides eletrônicos, em apresentações produzidas por professores.

\section{Método}

Para Figueiredo et al. (2005, p. 129), "metodologia é o conjunto de métodos ou caminhos que devem ser percorridos na busca do conhecimento. ”É aqui que procuraremos responder de uma só vez a questões, tais como: Quem? Como? Onde? Com quê?

Diante da dialética abordada na introdução, busca-se nesta pesquisa, entender como acontece o processo de produção de conteúdos multimídia em slides por meio de software de apresentação, procurando investigar quem produz, como produz, o que produz.

As decisões teóricas e metodológicas serão norteadas pela seguinte questão:

De que modo uma formação midiática experimental de licenciandos repercute na aquisição de competências para produzir e refletir sobre slides de apresentações multimídia em educação?

\section{Participantes}

Esta investigação tem como campo empírico o IFRN, onde são oferecidas várias modalidades de cursos para vários níveis acadêmicos e faixa etárias. Dentre as ofertas, destacam-se: Cursos de Qualificação Profissional e Graduação, Tecnologias, Licenciaturas e Pós-graduação; além de cursos de extensão para as comunidades interna e externa.

Além do seu corpo profissional de professores graduados, especialistas, mestres e doutores, que atuam nos diversos cursos, o IFRN tem também Professores em Formação Inicial, estudando Espanhol e Geografia e outras licenciaturas. É este universo de alunos, (duas turmas, uma de licenciandos em Espanhol e outra em Geografia), futuros professores, estudantes do quarto período, que compõem os sujeitos participantes desta investigação (amostra por conveniência).

\section{Instrumentos/Materiais}

Após a seleção da amostra, algumas técnicas e instrumentos metodológicos foram utilizados para a coleta de dados que permitirão uma combinação e triangulação de informações. Foram usadas: (a) a técnica do inquérito por questionário (incluindo pré-testes de conhecimentos) e entrevista semiestruturada; (b) a observação direta (do processo de produção, com registro de notas em diário do investigador), além da produção de diário dos participantes, com comentários sobre cada atividade. A análise dos documentos está sendo feita recorrendo ao uso de grades/grelhas para análise das apresentações multimídia.

A importância dos dados, segundo Marconi et al. (2003, p. 167) “está não em si mesmos, mas em proporcionarem respostas às investigações. ” Os dados já foram coletados, agora eles serão classificados de forma crítica e sistemática e receberão tratamento através de Grades/grelhas de análise para investigar as relações entre o fenômeno estudado e outros fatores, na dimensão das relações entre causa e efeito, produtor e produto, das inter-relações subjacentes à análise do conteúdo e os elos com as teorias.

Para garantir a ética relativa aos sujeitos da investigação, por ocasião do tratamento e publicação dos resultados, será utilizada a técnica operacional de codificação dos dados, atribuindo-lhes códigos.

Diante deste processo, será feita uma interpretação do material obtido, de forma que possa permitir uma generalização dos resultados em consonância, ou rejeição, ao referencial teórico, o que permitirá expor quais foram as melhores práticas, os impactos causados nos sujeitos, na sua reflexividade em relação às suas produções, bem como as implicações e as recomendações para futuros trabalhos.

\section{Procedimentos}

Esta investigação pressupõe uma posição epistemológica com enfoque de natureza qualitativa, ancorada numa metodologia de pesquisa-ação que proporciona elementos para, segundo Tripp (2005, p. 459), "completar um estudo de caso" a ser narrado, nos 
quais os dados coletados serão submetidos a uma única base de análise e interpretação. Yin (2010, p. 87), denomina essa modalidade de "projeto de métodos mistos”.

De acordo com Descombe (2002, p. 27. apud Bell, 2008, p.16), o objetivo da pesquisa-ação é “chegar a recomendações para uma boa prática, que lide com um problema ou melhore o desempenho da organização e dos indivíduos por meio de mudanças nas regras e procedimentos em que operam”. Esta abordagem está em consonância com os objetivos estabelecidos para esta investigação, em função dos benefícios que trarão para ambas as instituições de pesquisa e ensino, o IFRN e a Universidade do Minho.

Os procedimentos que envolvem as Etapas da Investigação já foram iniciados com a elaboração do projeto e a definição dos objetivos da investigação. Uma revisão sistemática da literatura está em andamento, o que permitiu a seleção dos instrumentos e da amostra de forma eficaz. A coleta de documentos em formato de arquivos digitais preliminares já ocorreu, o que permitirá uma análise detalhada dos documentos em formato de arquivos digitais. No processo também foram aplicados e serão analisados o questionário pré-teste. Em seguida foi aplicado o programa de intervenção pedagógica que será analisado junto com todos os materiais produzidos e coletados para só então serem redigidas as conclusões da investigação de forma a que possam ser apresentadas em momento e local adequados.

\section{Resultados e Discussão}

Faltando mais de um ano para o término desta investigação, ainda não é possível apresentar resultados conclusivos, tendo em vista que a etapa da análise dos dados coletados precisa ser implementada.

Entretanto, uma análise superficial dos documentos em formato de arquivos digitais já coletados, apresenta uma gama significativa de elementos relacionados a inconsistências no design de conteúdos áudio-scripto-visuais presentes nas apresentações produzidas com o senso comum. Por outro lado, as leituras preliminares dos materiais produzidos, após a formação pedagógica, apontam, tanto para uma melhora significativa na produção dos materiais digitais, quanto na criticidade dos participantes. Esta análise preliminar dos dados, nos tem revelado fortes indícios que indicam a aquisição, por parte dos sujeitos, de dois tipos de competências impactantes:

(a) Competência para Produzir suas próprias apresentações multimidiáticas para projeção vertical, baseando-se em planejamento sistemático e na "reflexão na ação”, e

(b) Competência para Analisar suas próprias apresentações multimidiáticas para projeção vertical, a partir de uma "reflexão sobre a ação".

Além disso, ao triangularmos algumas declarações de participantes, percebemos a existência de indícios que corroboram a aquisição destas competências, como demonstram estes dois exemplos obtidos nas falas dos participantes:

(a) P1. "... tenho um senso crítico mais apurado agora, na hora de analisar uma apresentação. ...Pude perceber uma mudança muito grande, com relação às apresentações passadas que a gente fez no curso."

(b) P2. "... e quanto a analisar agora, eu já tenho uma melhor visão, pra criticar, fazer uma análise crítica e também uma melhor forma de fazer apresentação desse material."

A análise dos dados é uma etapa importante no processo de investigação para atingirmos os nossos objetivos, entretanto, a aquisição de repertório teórico, proveniente da literatura científica, consome muito tempo, mas faz-se necessária para que as análises sejam feitas com eficiência, antes da publicação das conclusões finais.

\section{Referências}

Abela, A. (2008). Advanced presentations by design: Creating communication that drives action. San Francisco, CA: Pfeiffer.

Alley, M. (2003). The Craft of Scientific Presentations. New York: Springer-Verlag.

Cloutier, J. (1975 [1965]) A Era de Emerec ou a Comunicação Audio-scripto-visual na hora dos self-media. Lisboa: ITE /MEIC

Figueiredo, A. M.; Souza, S.R.G. (2005). Como elaborar projetos, monografias, dissertações e teses: da redação científica à apresentação do texto final. Rio de Janeiro: Lumen Júris.

Gabriel, M. (2013). Educ@r: a (r)evolução digital na educação. São Paulo, SP: Saraiva.

IFRN. (2012). Projeto Pedagógico do Curso Superior de Licenciatura em Espanhol Modalidade Presencial. Natal/RN: IFRN. Acessado em: 16/06/2015. Disponível em: http://portal.ifrn.edu.br/ensino/cursos/cursos-de graduacao/licenciatura/licenciatura-em-espanh ol/view

Kosslyn S. M. (2007). Clear and to the Point: 8 Psychological Principles. New York, NY; Oxford University Press.

Lefrançois, G. R. (2009). Teorias da Aprendizagem. 5 ed. São Paulo: CENGAGE Learning.

Marconi, M. A.; Lakatos, E. M. (2003). Fundamentos de metodologia científica. 5 ed. São Paulo: Atlas.

Mayer, R. E. (2009). Multimedia learning. 2nd ed. Cambridge, England: Cambridge University Press.

Peery, A. (2011). Creating Effective Presentations: Staff Development with Impact. Lanham, MD.: Rowman \& Littlefield Education.

Saettler, P. (2004). The Evolution of American Educational Technology. Englewood, Co.: Libraries Unlimited, Inc.

Shannon, C.E., \& Weaver, W. (1949). The mathematical theory of communication. Urbana: University of Illinois Press.

Schön, D. (1983). The Reflective Practitioner: how professionals thinkin action. New York: Basic Books. 
Schön, D. (2000). Educando o profissional reflexivo: um novo design para o ensino e a aprendizagem. Porto Alegre: Artmed.

Sweller, J. (2005). Implications of Cognitive Load for Multimedia Learning, in The Cambridge Handbook of Multimedia Learning, Richard E. Mayer, Ed., pp. 19-30 (Cambridge University Press, 2005).

Tripp, D. (2005). Pesquisa-Ação: uma introdução metodológica. Faculdade de Educação da Universidade de Murdoch, Austrália. Acessado em: 16/06/2015. Disponível em: http://www.redalyc.org/articulo.oa?id=298313 09

Tufte, E. R. (2006). Beautiful Evidence. Cheshire, CT: Graphics Press.

UNESCO. (2011). UNESCO ICT Competency Framework for Teachers. Paris: UNESCO. Acessado em: 16/06/2015. Disponível em: http://unesdoc.unesco.org/images /0021/002134/213475E.pdf
Zheng, R. (2009). Cognitive Effects of Multimedia Learning. Hersey, PA: Information Science.

Williams, R. (2008). The Non-Designer's Design Book. 3rd ed. Berkeley, CA: Peachpit Press.

Yin, R. K. (2010). Estudo de caso: planejamento e métodos. $4^{\mathrm{a}}$ ed. Porto Alegre: Bookman.

Nota: As citações das obras em língua inglesa configuram-se em traduções livre dos autores. 